\title{
Translational and internal energy distributions of methyl and hydroxyl radicals produced by 157 nm photodissociation of amorphous solid methanol
}

\section{$\operatorname{AUTHOR}(\mathrm{S}):$}

Hama, Tetsuya; Yokoyama, Masaaki; Yabushita, Akihiro; Kawasaki, Masahiro; Wickramasinghe, Piyumie; Guo, Wei; Loock, Hans-Peter; Ashfold, Michael N. R.; Western, Colin M.

\section{CITATION:}

Hama, Tetsuya ...[et al]. Translational and internal energy distributions of methyl and hydroxyl radicals produced by $157 \mathrm{~nm}$ photodissociation of amorphous solid methanol. JOURNAL OF CHEMICAL PHYSICS 2009, 131(22): 224512.

\section{ISSUE DATE:}

2009-12

\section{URL:}

http://hdl.handle.net/2433/109880

\section{RIGHT:}

Copyright 2009 American Institute of Physics. This article may be downloaded for personal use only. Any other use requires prior permission of the author and the American Institute of Physics. The following article appeared in JOURNAL OF CHEMICAL PHYSICS 131, 224512 (2009) and may be found at http://link.aip.org/link/JCPSA6/v131/i22/p224512/s1 


\title{
Translational and internal energy distributions of methyl and hydroxyl radicals produced by $157 \mathrm{~nm}$ photodissociation of amorphous solid methanol
}

\author{
Tetsuya Hama, ${ }^{1}$ Masaaki Yokoyama, ${ }^{1}$ Akihiro Yabushita, ${ }^{1}$ Masahiro Kawasaki, $\left.{ }^{1}, \mathrm{a}\right)$ \\ Piyumie Wickramasinghe, ${ }^{2}$ Wei Guo, ${ }^{2}$ Hans-Peter Loock, ${ }^{2}$ Michael N. R. Ashfold, ${ }^{3}$ and \\ Colin M. Western ${ }^{3}$ \\ ${ }^{1}$ Department of Molecular Engineering, Kyoto University, Kyoto 615-8510, Japan \\ ${ }^{2}$ Department of Chemistry, Queen's University, Kingston, Ontario K7L 3N6, Canada \\ ${ }^{3}$ School of Chemistry, University of Bristol, Bristol BS8 1TS, United Kingdom
}

(Received 7 July 2009; accepted 17 October 2009; published online 10 December 2009)

\begin{abstract}
Methanol is typically observed within water-rich interstellar ices and is a source of interstellar organic species. Following the $157 \mathrm{~nm}$ photoexcitation of solid methanol at $90 \mathrm{~K}$, desorbed $\mathrm{CH}_{3}(v=0)$ and $\mathrm{OH}(v=0,1)$ radicals have been observed in situ, near the solid surface, using resonance-enhanced multiphoton ionization (REMPI) detection methods. Time-of-flight and rotationally resolved REMPI spectra of the desorbed species were measured, and the respective fragment internal energy and kinetic energy distributions were obtained. Photoproduction mechanisms for $\mathrm{CH}_{3}$ and $\mathrm{OH}$ radicals from solid methanol are discussed. The formation of $\mathrm{O}\left({ }^{1} D\right.$ and $\left.{ }^{3} P\right)$ atoms and $\mathrm{H}_{2} \mathrm{O}$ was investigated, but the yield of these species was found to be negligible. $\mathrm{CH}_{3}$ products arising following the photoexcitation of water-methanol mixed ice showed similar kinetic and internal energy distributions to those from neat methanol ice. (C) 2009 American Institute of Physics. [doi:10.1063/1.3259877]
\end{abstract}

\section{INTRODUCTION}

Methanol is the smallest closed shell alcohol and has long served as a model for the dissociation of organic molecules. There is a comparably large body of literature on the vacuum ultraviolet (VUV) photolysis of methanol in the gas phase. ${ }^{1-6}$ The results of the gas phase methanol photolysis studies at $157 \mathrm{~nm}$ showed that the relative contribution of the atomic hydrogen elimination process is larger than that of the molecular hydrogen elimination process, i.e., the ratio is $1: 0.21 .^{2} \mathrm{C}-\mathrm{O}$ bond cleavage [reaction (1)] is another primary photoprocess following excitation of the $2{ }^{1} \mathrm{~A}^{\prime \prime}-X^{1} \mathrm{~A}^{\prime \prime}$ transition in the 151-163 nm region, where it competes with the atomic and molecular hydrogen elimination processes,

$$
\mathrm{CH}_{3} \mathrm{OH}+h \nu \rightarrow \mathrm{CH}_{3}+\mathrm{OH} \text {. }
$$

The relative contribution of the $\mathrm{C}-\mathrm{O}$ bond cleavage channel in the gas phase photolysis at $157 \mathrm{~nm}$ has yet to be determined. ${ }^{2,3}$ Reaction (1) was also observed following the photoexcitation of $\mathrm{CH}_{3} \mathrm{OH}$ in various rare-gas matrices at $4 \mathrm{~K}$ and the photodissociation threshold energy for reaction (1) identified at $\lambda \sim 175 \mathrm{~nm}^{7}$. Since methanol is known to be a component of the icy mantle on interstellar grains, comets, and other solar system bodies, ${ }^{8-11}$ the effects of irradiating pure methanol ice by electrons, ions, and UV photons have each received much experimental study. ${ }^{12-16}$

Compared to the gas phase, however, the photochemical processes occurring in condensed phase samples of $\mathrm{CH}_{3} \mathrm{OH}$ are more complicated because of the many possible second-

\footnotetext{
${ }^{a)}$ Author to whom correspondence should be addressed. Electronic mail: kawasaki@moleng.kyoto-u.ac.jp. FAX: +81-75-383-257.
}

ary reactions on/in solid $\mathrm{CH}_{3} \mathrm{OH} .{ }^{15,16} \mathrm{UV}$ absorption of methanol in the condensed phase is observed at wavelengths shorter than the $\sim 185 \mathrm{~nm}$ threshold. ${ }^{17}$ Gerakines et al. reported VUV $(\lambda>110 \mathrm{~nm})$ photolysis studies of solid $\mathrm{CH}_{3} \mathrm{OH}$ at $10 \mathrm{~K}$. Hydrogen $\left(\mathrm{H}_{2}\right)$, carbon monoxide $(\mathrm{CO})$, carbon dioxide $\left(\mathrm{CO}_{2}\right)$, formyl radical $(\mathrm{HCO})$, formaldehyde $\left(\mathrm{H}_{2} \mathrm{CO}\right)$, methane $\left(\mathrm{CH}_{4}\right)$, and methyl formate $\left(\mathrm{CH}_{3} \mathrm{OCHO}\right)$ were detected as products by in situ infrared (IR) absorption spectroscopy, but $\mathrm{CH}_{3}$ and $\mathrm{OH}$ radicals were not. ${ }^{16} \mathrm{CH}_{4}$ production from VUV photolysis of solid methanol was reported to scale linearly with irradiation time. ${ }^{15,16}$ Unimolecular photodissociation,

$$
\mathrm{CH}_{3} \mathrm{OH}+h \nu \rightarrow \mathrm{CH}_{4}\left(X^{1} \mathrm{~A}_{1}\right)+\mathrm{O}\left({ }^{1} D\right),
$$

is thus one plausible $\mathrm{CH}_{4}$ formation mechanism. As Gerakines et al. noted, however, further research is necessary since gas phase photolysis studies have failed to reveal any evidence of reaction $(2)^{2,3,16}$

To obtain a more complete mechanism understanding of amorphous solid methanol (ASM) photolysis-including possible secondary reactions on/in ASM-it would be helpful to determine the kinetic and internal energy distributions of the photoproducts generated from the primary photodissociation of ASM. Hama et al. previously used sensitive resonance-enhanced multiphoton ionization (REMPI) methods to determine the translational and internal energy distributions of, and thus formation mechanisms for, photodesorbed $\mathrm{H}$ atoms and $\mathrm{H}_{2}$ molecules following VUV photolysis of ASM. ${ }^{18}$

In this paper, we investigate the mechanisms, the dynamics of production and the possible reactions of $\mathrm{CH}_{3}$ and $\mathrm{OH}$ 


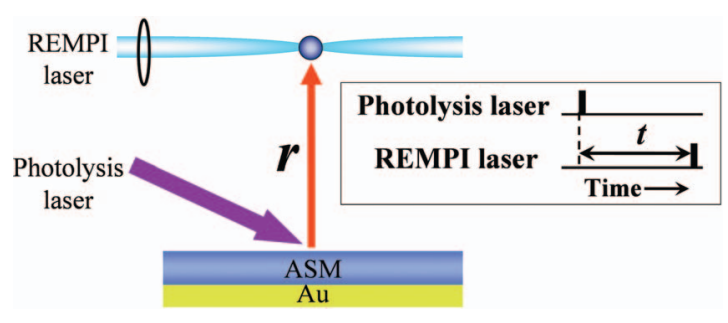

FIG. 1. Schematic illustration of the experiment. Photofragments from the $157 \mathrm{~nm}$ photodissociation of ASM are detected by the REMPI technique. The timing plot for measurements of a TOF spectrum is shown in the inset where the delay time $t$ between photolysis and probe laser pulses corresponds to the TOF. $r$ is the vertical distance between the disk substrate and the REMPI detection point. The VUV photoirradiated area is a disk with a radius of $6 \mathrm{~mm}$.

products following $157 \mathrm{~nm}$ photodissociation of ASM at $90 \mathrm{~K}$, using REMPI methods to determine their respective translational energy distributions and internal state population distributions. Possible secondary reactions on/in ASM are discussed in light of the obtained results. An attempt was also made to detect $\mathrm{O}\left({ }^{1} D\right)$ and $\mathrm{O}\left({ }^{3} P\right)$ atoms and $\mathrm{H}_{2} \mathrm{O}$ products.

\section{EXPERIMENTAL}

\section{A. Apparatus and preparation of ice films}

The apparatus has been described before, and only details relevant to the present experiments are given here. ${ }^{19} \mathrm{As}$ shown in the schematic diagram of the experimental arrangement (Fig. 1), photodesorbed products were ionized at the focal point of the REMPI probe laser light, which was separated from the ice surface by a vertical distance of $r$. ASM was prepared by backfilling deposition of methanol vapor onto the gold substrate at $90 \mathrm{~K}$ for $60 \mathrm{~min}$. The exposure was typically $1500 \mathrm{~L}\left(1 \mathrm{~L}=1 \times 10^{-6}\right.$ Torr s) to exclude the influence of reactions at the ASM/substrate interface. ${ }^{20,21}$

Since crystallization of solid methanol occurs at temperatures above $103.4 \mathrm{~K}$, the morphology of the prepared solid methanol is amorphous. ${ }^{22}$ Unfocused $157 \mathrm{~nm}$ laser (Lambda Physik, OPTexPro) radiation with a pulse duration of $10 \mathrm{~ns}$ [full width at half maximum (FWHM)] was incident on the ice surface at an angle of $\sim 80^{\circ}$ to the surface normal and at a fluence, $F<0.1 \mathrm{~mJ}$ ( $\sim 10^{14}$ photons) $\mathrm{cm}^{-2}$ pulse ${ }^{-1}$, which roughly corresponds to that in molecular clouds over $\sim 10^{4} \mathrm{yr}^{23} \mathrm{CH}_{3}$ photoproducts were ionized at a distance of $r=2 \mathrm{~mm}$ from the substrate surface $(4 \mathrm{~mm}$ for the case of $\mathrm{OH}$ products). $\mathrm{CH}_{3}$ products were detected by $(2+1)$ REMPI via the $4 p_{\mathrm{z}}{ }^{2} \mathrm{~A}_{2}^{\prime}\left(v^{\prime}=0\right) \leftarrow X^{2} \mathrm{~A}_{2}^{\prime \prime}\left(v^{\prime \prime}=0\right)$ transition in the wavelength range of $285.0-287.0 \mathrm{~nm}$ and collected with a small mass spectrometer aligned perpendicular to the ice surface. ${ }^{24} \mathrm{OH}$ products were probed by $(2+1)$ REMPI via the $\quad D^{2} \Sigma^{-}\left(v^{\prime}=0\right) \leftarrow X^{2} \Pi\left(v^{\prime \prime}=0\right) \quad$ transition at $243.5-245.0 \mathrm{~nm}$ and via the $D^{2} \Sigma^{-}\left(v^{\prime}=1\right) \leftarrow X^{2} \Pi\left(v^{\prime \prime}=0\right)$ and $3{ }^{2} \Sigma^{-}\left(v^{\prime}=0\right) \leftarrow X^{2} \Pi\left(v^{\prime \prime}=1\right)$ transitions in the wavelength range of $237.5-237.7 \mathrm{~nm} .{ }^{25}$ PGOPHER, a program for simulating rotational structure, ${ }^{26}$ was used to simulate the measured spectra and thereby establish the product rotational temperatures. Detection of $\mathrm{O}\left({ }^{1} D_{2}\right), \mathrm{O}\left({ }^{3} P_{J=2,1,0}\right)$ atoms and $\mathrm{H}_{2} \mathrm{O}$ molecules was attempted also by $(2+1)$ REMPI via the
$\mathrm{O}\left({ }^{1} F_{3} \leftarrow{ }^{1} D_{2}\right)$ transition at $203.8 \mathrm{~nm}$, the $\mathrm{O}\left({ }^{3} P_{J}-{ }^{3} P_{J}\right)$ transition at $225.6-226.4 \mathrm{~nm}$, and the $C(000)-X(000)$ transition at $247.3-248.6 \mathrm{~nm}$, respectively, ${ }^{27-29}$ but no signal was observed. Photodesorption of $\mathrm{O}\left({ }^{1} D_{2}\right), \mathrm{O}\left({ }^{3} P_{J=2,1,0}\right)$ atoms, and $\mathrm{H}_{2} \mathrm{O}$ molecules has been previously observed with the same REMPI setup following the $157 \mathrm{~nm}$ photolysis of $\mathrm{H}_{2} \mathrm{O}$ ice at $90 \mathrm{~K}^{29-31}$

Recognizing that photoproducts might accumulate on the ASM surface after prolonged irradiation by $157 \mathrm{~nm}$ photolysis pulses, and that the photochemistry of these products might influence the measured product (state) distributions, the ASM surface was continually refreshed by intermissive exposure to $\mathrm{CH}_{3} \mathrm{OH}$ vapor. In the present experiments, the pulsed valve was opened after each laser shot so as to deposit a fresh layer of ASM.

For the $\mathrm{CH}_{3} \mathrm{OH} / \mathrm{H}_{2} \mathrm{O}$ codeposited ice photolysis experiments, $\mathrm{CH}_{3} \mathrm{OH} / \mathrm{H}_{2} \mathrm{O}$ (1:1 mixture) vapor was deposited on the gold substrate. As before, the exposure was typically $1500 \mathrm{~L}$ and, again, fresh surfaces of cocondensed $\mathrm{CH}_{3} \mathrm{OH} / \mathrm{H}_{2} \mathrm{O}$ were prepared as described above. All of the present photolysis experiments were performed at a sample temperature of $90 \mathrm{~K}$, and the chamber pressure was $5 \times 10^{-7}$ Torr (due to the intermissive $\mathrm{CH}_{3} \mathrm{OH}$ or $\mathrm{CH}_{3} \mathrm{OH} / \mathrm{H}_{2} \mathrm{O}$ vapor injection into the chamber).

\section{B. Simulation of $(2+1)$ REMPI spectra}

$\mathrm{CH}_{3}$ products were monitored by $(2+1)$ REMPI via the $4 p_{\mathrm{z}}{ }^{2} \mathrm{~A}_{2}^{\prime \prime}\left(v^{\prime}=0\right) \leftarrow X^{2} \mathrm{~A}_{2}^{\prime \prime}\left(v^{\prime \prime}=0\right)$ transition. Spectral simulation employed the program PGOPHER (Ref. 26) and the spectroscopic constants reported by Black and Powis. ${ }^{24}$ The $4 p_{\mathrm{z}}{ }^{2} \mathrm{~A}_{2}^{\prime \prime}\left(v^{\prime}=0\right)$ state predissociates with a level dependent efficiency. ${ }^{24}$ This affects the measured REMPI line intensities and linewidths such that the latter vary as $\left\{0.4+0.08\left[N(N+1)-K^{2}\right]\right\}\left(\right.$ in $\left.\mathrm{cm}^{-1}\right)$, while the former declines by the square of this term. The measured spectra show evidence of power broadening also, which we accommodate by further broadening each transition with a Lorentzian function $\left(3 \mathrm{~cm}^{-1}\right.$ FWHM $)$ and by reducing the relative weighting of the zero rank component of this two-photon transition. The two-photon transition probability is carried by two (a zero and a second rank) components. The former contributes only to the intense central $Q$ branch (which is noticeably saturated under the present conditions), while the latter gives rise to $O, P, Q, R$, and $S$ branches.

The REMPI features associated with $\mathrm{OH}$ products were also assigned and simulated using literature constants for the relevant electronic states. ${ }^{25,32}$ The two-photon absorption cross sections reported by Greenslade et al. ${ }^{25}$ allow estimation of the $\left(v^{\prime \prime}=1\right) /\left(v^{\prime \prime}=0\right)$ branching ratio in the $\mathrm{OH}$ products.

\section{Simulation of time-of-flight spectra of photoproducts}

Time-of-flight (TOF) spectra of the $\mathrm{CH}_{3}$ and $\mathrm{OH}$ photoproducts were taken as a function of time $t$ between the photolysis and REMPI laser pulses using a delay generator (Stanford Research) in order to investigate the flight times and thus translational energies of the desorbing photoprod- 


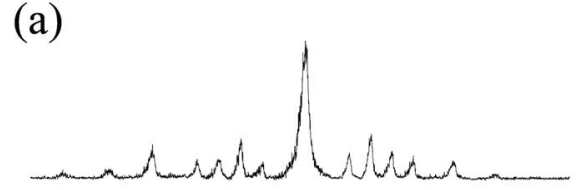

(b)

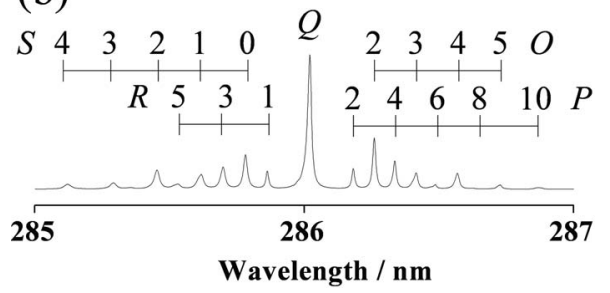

FIG. 2. (a) $(2+1)$ REMPI excitation spectrum of $\mathrm{CH}_{3}$ radicals from the $157 \mathrm{~nm}$ photolysis of a fresh ASM sample at $90 \mathrm{~K}$, recorded at $t=6.0 \mu \mathrm{s}$. (b) Simulated REMPI excitation spectrum of $\mathrm{CH}_{3}$ radicals, resonance enhanced at the two photon energy by the $4 p_{\mathrm{z}}{ }^{2} \mathrm{~A}_{2}^{\prime \prime}\left(v^{\prime}=0\right)$ level, assuming a Boltzmann distribution rotational state population distribution with $T_{\text {rot }}=150 \mathrm{~K}$.

ucts as shown schematically in Fig. 1. The measured TOF spectra, $S\left(a_{\mathrm{i}}, t, T_{\text {trans }}\right)$, of the $\mathrm{CH}_{3}$ and $\mathrm{OH}$ products were fitted to a sum of one or more flux-weighted MaxwellBoltzmann $(\mathrm{MB})$ distributions, $S_{\mathrm{MB}}$, each defined by a translational temperature, $T_{\text {trans }}$. Details regarding the simulation of such TOF spectra have been reported previously. ${ }^{19}$ The coefficients, $a_{\mathrm{i}}$, define the relative population associated with each MB component,

$$
\begin{aligned}
& S\left(a_{\mathrm{i}}, t, T_{\text {trans }}\right)=\Sigma a_{\mathrm{i}} S_{\mathrm{MB}}\left(t, T_{\text {trans }}\right), \\
& S_{\mathrm{MB}}\left(t, T_{\text {trans }}\right)=r^{3} t^{-4} \exp \left[-m r^{2} / 2 k_{\mathrm{B}} T_{\text {trans }} t^{2}\right],
\end{aligned}
$$

where $r$ is the flight distance. The MB distribution, $P_{\mathrm{MB}}\left(E_{\mathrm{t}}\right)$, as a function of translational energy, $E_{\mathrm{t}}$, is characterized by the averaged translational energy, $\left\langle E_{\mathrm{t}}\right\rangle=2 k_{\mathrm{B}} T_{\text {trans }}$, where $k_{\mathrm{B}}$ is the Boltzmann constant, ${ }^{33}$

$$
P_{\mathrm{MB}}\left(E_{\mathrm{t}}\right)=\left(k_{\mathrm{B}} T_{\text {trans }}\right)^{-2} E_{\mathrm{t}} \exp \left[-E_{\mathrm{t}} / k_{\mathrm{B}} T_{\text {trans }}\right] .
$$

Conversion from the $E_{\mathrm{t}}$ distribution to the TOF distribution was performed using the Jacobian listed by Zimmerman and Ho. $^{34}$

In these calculations for details, we assume that signals come from a disk (VUV photoirradiation area) with a radius of $6 \mathrm{~mm}$. Hence, an effective flight length is given by $\left(r^{2}\right.$ $\left.+R^{2}\right)^{1 / 2}$ and the detection probability is proportional to $2 \pi R \mathrm{~d} R /\left(r^{2}+R^{2}\right)$, where $r=2$ and $4 \mathrm{~mm}$ for the case of $\mathrm{CH}_{3}$ and $\mathrm{OH}$ products, respectively, and $0 \leqslant R \leqslant 6 \mathrm{~mm}$. ${ }^{19}$ The variable $R$ is the radius of the irradiation area which was defined in Ref. 19. For the angular distribution of the photofragments from the ice surface, $\cos ^{n} \theta$, where $\theta$ is the surface polar coordinate, $n=0$ was adopted in the best-fitting procedures because the parent $\mathrm{CH}_{3} \mathrm{OH}$ molecules adsorb randomly on the ASM surfaces. ${ }^{19,35}$

\section{RESULTS}

\section{A. Kinetic energy and rotational energy distributions of the $\mathrm{CH}_{3}$ radical}

Figure 2(a) shows a rotationally resolved REMPI spectrum of $\mathrm{CH}_{3}\left(v^{\prime \prime}=0\right)$ products formed following the $157 \mathrm{~nm}$

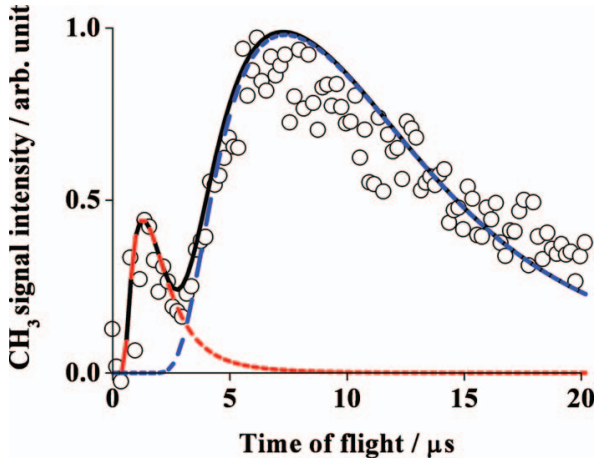

FIG. 3. TOF spectrum of $\mathrm{CH}_{3}$ radicals from the $157 \mathrm{~nm}$ photolysis of a fresh ASM sample, monitoring on the $Q$ branch of the $(2+1)$ REMPI spectrum shown in Fig. 2. The solid curves are fits to the data derived assuming two MB distributions with $T_{\text {trans }}=3000 \mathrm{~K}(10 \%)$ and $90 \mathrm{~K}(90 \%)$. The vertical flight distance used in these experiments is $2 \mathrm{~mm}$.

photolysis of freshly deposited ASM recorded at a fixed delay of $t=6.0 \mu \mathrm{s}$. The spectrum is readily assignable to the $4 p_{\mathrm{z}}{ }^{2} \mathrm{~A}_{2}^{\prime \prime}\left(v^{\prime}=0\right) \leftarrow X^{2} \mathrm{~A}_{2}^{\prime \prime}\left(v^{\prime \prime}=0\right)$ transition; ${ }^{24,36}$ the best-fit simulation is shown in Fig. 2(b). The rotational temperature, $T_{\text {rot }}$ is estimated to be $150 \pm 50 \mathrm{~K} \quad\left(\left\langle E_{\text {rot }}\right\rangle\right.$ $\left.=1.2 \pm 0.4 \mathrm{~kJ} \mathrm{~mol}^{-1}\right)$ by comparison with the spectral simulation. Figure 3 shows a typical TOF spectrum of the $\mathrm{CH}_{3}$ products monitored at a REMPI wavelength of $286.0 \mathrm{~nm}$ (i.e., in the congested $Q$ branch), which is reproduced well by a sum of two MB distributions with $T_{\text {trans }}$ $=3000 \pm 1000 \mathrm{~K} \quad\left(\left\langle E_{\text {trans }}\right\rangle=49.9 \pm 16.6 \mathrm{~kJ} \mathrm{~mol}^{-1}\right) \quad$ and $90 \pm 20 \mathrm{~K}\left(\left\langle E_{\text {trans }}\right\rangle=1.5 \pm 0.3 \mathrm{~kJ} \mathrm{~mol}^{-1}\right)$. Table I summarizes these results. Changing the REMPI probe wavelength, e.g., to the $S(2)$ line at $285.45 \mathrm{~nm}$, led to no appreciable change in the TOF profile. We were unable to characterize the rotational resolved REMPI spectrum for the $T_{\text {trans }}=3000 \mathrm{~K}$ component in terms of a specific $T_{\text {rot }}$ because of the weak signal intensity.

\section{B. Kinetic energy and rotational distributions of the $\mathrm{OH}$ radical}

Figure 4(a) shows a rotationally resolved REMPI spectrum of the $\mathrm{OH}(v=0)$ products recorded at $t=2.0 \mu$ s, i.e., at the maximum of the single peak in their TOF spectrum. Spectral simulation [Fig. 4(b)] returns a best-fit rotational temperature $T_{\text {rot }}(v=0)=300 \mathrm{~K}$, and the rotational temperature $T_{\text {rot }}(v=0)$ is estimated to be $300 \pm 100 \mathrm{~K}$ by spectral simulation $\left(\left\langle E_{\text {rot }}\right\rangle=2.5 \pm 0.8 \mathrm{~kJ} \mathrm{~mol}^{-1}\right)$. Figures 5(a) and 5(b) show typical TOF spectra of the $\mathrm{OH}(v=0)$ and $\mathrm{OH}(v=1)$

TABLE I. Translational and rotational temperatures and energies of $\mathrm{CH}_{3}(v=0)$ products.

\begin{tabular}{lccc}
\hline \hline & $\begin{array}{c}\text { Translational } \\
\text { energy } \\
E_{\mathrm{T}} \\
\text { Time-of-flight component, } \\
\text { contributions }\end{array}$ & $\begin{array}{c}\text { Rotational } \\
\text { temperature } \\
\left.\mathrm{kJ} \mathrm{mol}^{-1}\right)\end{array}$ & $\begin{array}{c}\text { Rotational } \\
\text { energy } \\
E_{\mathrm{R}}\end{array}$ \\
\hline $\mathrm{CH}_{3}\left(T_{\text {trans }}=3000 \mathrm{~K}\right), 10 \%$ & $49.9 \pm 16.6$ & $\mathrm{a}$ & $\mathrm{a}$ \\
$\mathrm{CH}_{3}\left(T_{\text {trans }}=90 \mathrm{KJ}\right), 90 \%$ & $1.5 \pm 0.3$ & $150 \pm 50^{\mathrm{b}}$ & $\left.1.2 \pm 0.4^{\mathrm{b}}\right)$ \\
\hline
\end{tabular}

The rotational spectrum could not be characterized by a specific $T_{\text {rot }}$ because of the weakness of the signal intensity.

${ }^{\mathrm{b}}$ From spectra recorded at $t=6.0 \mu \mathrm{s}$. 


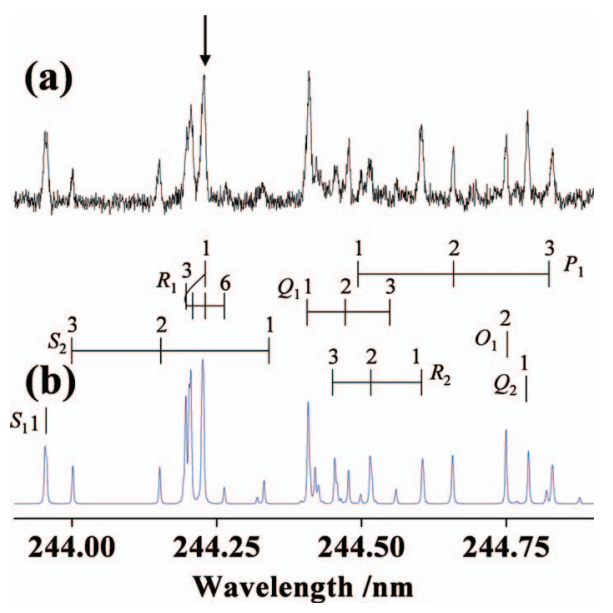

FIG. 4. (a) $(2+1)$ REMPI excitation spectrum of $\mathrm{OH}$ radicals from the $157 \mathrm{~nm}$ photolysis of a fresh ASM sample at $90 \mathrm{~K}$, recorded at $t=2.0 \mu \mathrm{s}$. (b) Simulation of the $D^{2} \Sigma^{-} \leftarrow X^{2} \Pi\left(v^{\prime}=0, v^{\prime \prime}=0\right)$ two-photon excitation spectrum of $\mathrm{OH}$ assuming a Boltzmann rotational state population distribution with $T_{\text {rot }}=300 \mathrm{~K}$. The arrow indicates the $R_{1}(1)+R_{1}(5)$ line used when measuring the TOF spectrum.

products monitoring, respectively, the $R_{1}(1)+R_{1}(5)$ line and the $R_{1}(2)$ line in the REMPI spectrum. Both are reproduced well by a single $\mathrm{MB}$ distribution with $T_{\text {trans }}=3000 \pm 500 \mathrm{~K}$ $\left(\left\langle E_{\text {trans }}\right\rangle=49.9 \pm 8.3 \mathrm{kcal} \mathrm{mol}^{-1}\right)$. No component with $T_{\text {trans }}$ $=90 \mathrm{~K}$ was detected, in contrast to $\mathrm{CH}_{3}$ products. Figure $6(\mathrm{a})$ shows another portion of the OH REMPI spectrum which contains overlapping contributions from both $\mathrm{OH}(v=0)$ and $\mathrm{OH}(v=1)$ products, recorded at $t=2.0 \mu \mathrm{s}$; the accompanying simulation [Fig. 6(b)] employs $T_{\text {rot }}(v=0)=300 \mathrm{~K}$ and $T_{\text {rot }}(v=1)=200 \mathrm{~K}$. The rotational temperature $T_{\text {rot }}(v=1)$ is estimated to be $200 \pm 50 \mathrm{~K}$ by spectral simulation $\left(\left\langle E_{\text {rot }}\right\rangle\right.$ $\left.=1.7 \pm 0.4 \mathrm{~kJ} \mathrm{~mol}^{-1}\right)$. The $\mathrm{OH}(v=1) / \mathrm{OH}(v=0)$ population ratio is determined to be $0.2 \pm 0.1$. Table II summarizes these results.

\section{Additional $157 \mathrm{~nm}$ photolysis experiments involving ASM}

To assess possible contributions from secondary processes on the ASM surface and in the bulk, additional experi-

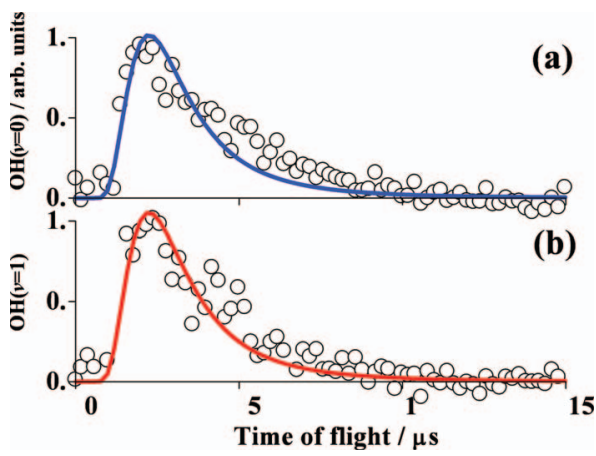

FIG. 5. TOF spectra of $\mathrm{OH}$ radicals from the $157 \mathrm{~nm}$ photolysis of a fresh ASM sample, obtained by monitoring (a) the $R_{1}(1)+R_{1}(5)$ line in the $\mathrm{OH}$ $D^{2} \Sigma^{-} \leftarrow X^{2} \Pi\left(v^{\prime}=0, v^{\prime \prime}=0\right)$ two-photon transition and (b) the $R_{1}(2)$ line in the OH $3^{2} \Sigma^{-} \leftarrow X^{2} \Pi\left(v^{\prime}=0, v^{\prime \prime}=1\right)$ two-photon transition. The solid curves are fits to the data derived assuming a $\mathrm{MB}$ translational energy distribution with $T_{\text {trans }}=3000 \mathrm{~K}$ in both cases. The vertical flight distance used in these experiments is $4 \mathrm{~mm}$.

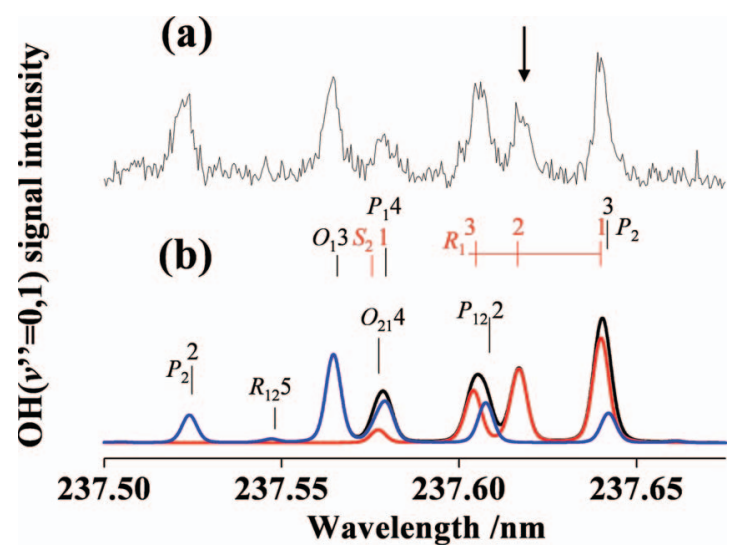

FIG. 6. (a) $(2+1)$ REMPI excitation spectrum of $\mathrm{OH}$ radicals from the $157 \mathrm{~nm}$ photolysis of a fresh ASM sample at $90 \mathrm{~K}$ recorded at $t=2.0 \mu \mathrm{s}$. (b) Simulation of relevant parts of the overlapping $D^{2} \Sigma^{-} \leftarrow X^{2} \Pi\left(v^{\prime}=1, v^{\prime \prime}=0\right)$ and $3{ }^{2} \Sigma^{-} \leftarrow X^{2} \Pi\left(v^{\prime}=0, v^{\prime \prime}=1\right)$ two-photon transitions of $\mathrm{OH}$ assuming Boltzmann rotational state population distribution with $T_{\text {rot }}\left(v^{\prime \prime}=0\right)=300 \mathrm{~K}$ (blue line) and $T_{\text {rot }}\left(v^{\prime \prime}=1\right)=200 \mathrm{~K}$ (red line). The black line is the sum of the spectral simulations. The arrow indicates the $R_{1}(2)$ line used when measuring the TOF spectrum.

ments were performed wherein TOF spectra of $\mathrm{CH}_{3}$ and $\mathrm{OH}$ products formed by $157 \mathrm{~nm}$ photolysis of ASM were measured after 30 min photoirradiation without the intermissive dosing of $\mathrm{CH}_{3} \mathrm{OH}$ vapor. No discernible differences were found in either the TOF spectra or the rotationally resolved REMPI spectra of the $\mathrm{CH}_{3}$ or $\mathrm{OH}$ products recorded with the fresh or photoirradiated ASM samples. These results support the views that (a) the observed $\mathrm{CH}_{3}$ and $\mathrm{OH}$ radicals are produced directly via the $\mathrm{C}-\mathrm{O}$ cleavage reaction (1) and (b) secondary photoprocesses on/in ASM make no contribution to the formation of these desorbing species.

REMPI signals attributable to $\mathrm{O}\left({ }^{1} D\right)$ and $\mathrm{O}\left({ }^{3} P\right)$ atoms were sought in the TOF range $0.5 \mu \mathrm{s} \leqslant t \leqslant 30 \mu \mathrm{s}$, but not observed. The primary formation of methane and $\mathrm{O}\left({ }^{3} \mathrm{P}\right)$ products is a spin-forbidden process, i.e.,

$$
\mathrm{CH}_{3} \mathrm{OH}+h \nu \rightarrow \mathrm{CH}_{4}\left(X^{1} \mathrm{~A}_{1}\right)+\mathrm{O}\left({ }^{3} P\right) .
$$

$\mathrm{O}\left({ }^{1} D\right)$ and $\mathrm{O}\left({ }^{3} P\right)$ atoms have been successfully detected with the same REMPI setup following the $157 \mathrm{~nm}$ photolysis of $\mathrm{H}_{2} \mathrm{O}$ or $\mathrm{H}_{2} \mathrm{O}_{2}$ ices films at $90 \mathrm{~K}^{30,31}$ The lack of detectable $\mathrm{O}\left({ }^{1} D\right)$ and $\mathrm{O}\left({ }^{3} P\right)$ atoms in the present methanol experiments is in accord with the results of gas phase methanol photolysis studies at $157 \mathrm{~nm}$ (Refs. 2 and 3) and suggests that the primary formation of methane and $\mathrm{O}\left({ }^{1} D\right)$ or $\mathrm{O}\left({ }^{3} P\right)$ products via reactions (2) and (6) plays at most a minor role.

To verify that the measured $\mathrm{CH}_{3}$ product state distributions are not affected by possible contamination from back-

TABLE II. Translational and rotational temperatures and energies of $\mathrm{OH}(v=0$ and 1$)$ products.

\begin{tabular}{lcccc}
\hline \hline & \multicolumn{2}{c}{$\mathrm{OH}(v=0)$} & $\mathrm{OH}(v=1)^{\mathrm{a}}$ \\
\cline { 2 - 5 } & Translation & Rotation & Translation & Rotation \\
\hline Temperature $(\mathrm{K})$ & $3000 \pm 500$ & $300 \pm 100^{\mathrm{b}}$ & $3000 \pm 500$ & $200 \pm 50^{\mathrm{b}}$ \\
Energy $\left(\mathrm{kJ} \mathrm{mol}^{-1}\right)$ & $49.9 \pm 8.3$ & $2.5 \pm 0.8$ & $49.9 \pm 8.3$ & $1.7 \pm 0.4$ \\
\hline \hline
\end{tabular}

${ }^{a}$ Population ratio $\mathrm{OH}(v=1) / \mathrm{OH}(v=0)=0.2 \pm 0.1$.

${ }^{\mathrm{b}}$ From spectra recorded at $t=2.0 \mu \mathrm{s}$. 
ground water vapor, the ASM sample was changed to a 1:1 mixture of $\mathrm{CH}_{3} \mathrm{OH} / \mathrm{H}_{2} \mathrm{O}$ ice. The intensities of the $T_{\text {trans }}$ $=3000$ and $90 \mathrm{~K}$ components of the $\mathrm{CH}_{3}$ radical TOF signal from the mixed sample were both reduced, and the majority of the $\mathrm{CH}_{3}$ products are accommodated to the substrate temperature $(90 \mathrm{~K})$ which was similar to that from pure, fresh ASM samples.

A similar check is not possible for the $\mathrm{OH}$ products because of the contribution from $\mathrm{OH}$ products formed by simultaneous photolysis of $\mathrm{H}_{2} \mathrm{O}$.

\section{DISCUSSION}

The $\mathrm{C}-\mathrm{O}$ bond cleavage has been observed as a primary process following photolysis of $\mathrm{CH}_{3} \mathrm{OH}$ both in the gas phase and in solid rare-gas matrices, ${ }^{2,3,7}$

$$
\begin{aligned}
\mathrm{CH}_{3} \mathrm{OH}(\mathrm{ads})+h \nu \rightarrow \mathrm{CH}_{3}(\mathrm{i})+\mathrm{OH}(\mathrm{i}), \\
\Delta H=422.6 \mathrm{~kJ} \mathrm{~mol}^{-1} .
\end{aligned}
$$

The available energy for reaction (7) at $157 \mathrm{~nm}\left(E_{\text {phot }}\right.$ $\left.=757.3 \mathrm{~kJ} \mathrm{~mol}^{-1}\right)$ is $E_{\text {avail }}(7)=334.7 \mathrm{~kJ} \mathrm{~mol}^{-1}$, calculated using liquid phase thermodynamic data for the condensed or adsorbed species ("ads") and gas phase data for species on the ASM/vacuum interface ("i"). ${ }^{39,40}$ The center of mass kinetic energy distribution of the $\mathrm{CH}_{3}$ and $\mathrm{OH}$ products resulting from $157 \mathrm{~nm}$ photolysis of gas phase $\mathrm{CH}_{3} \mathrm{OH}$ shows maximum probability at $217.6 \mathrm{~kJ} \mathrm{~mol}^{-1}$ and extends to $372.4 \mathrm{~kJ} \mathrm{~mol}^{-1}$, which is consistent with the gas phase value for $E_{\text {avail }}(7){ }^{2,3}$ This translational energy is partitioned between the $\mathrm{CH}_{3}$ and $\mathrm{OH}$ fragments according to momentum conservation, such that the most probable fragment translational energies are, respectively, 117.2 and $100.4 \mathrm{~kJ} \mathrm{~mol}^{-1}$. These values are much higher than those found in the present condensed phase study with $E_{\text {avail }}(7)=334.7 \mathrm{~kJ} \mathrm{~mol}^{-1}$, wherein we determine an average center of mass translational energy for the photodesorbed $\mathrm{CH}_{3}$ and $\mathrm{OH}$ products of only $99.6 \mathrm{~kJ} \mathrm{~mol}^{-1}$. This reduced partitioning of $E_{\text {avail }}(7)$ into product translational energy could be due to cage effects and the dissipation of available energy into the ASM bulk. ${ }^{7,17}$

Hama et al. performed direct measurements of photodesorbed hydrogen atoms and molecules following VUV photolysis of amorphous solid $\mathrm{CH}_{3} \mathrm{OH}$ and $\mathrm{CD}_{3} \mathrm{OH} .{ }^{18}$ The results showed that $\mathrm{H}$ and $\mathrm{D}$ atoms are produced via reactions (8) and (9),

$$
\begin{aligned}
& \mathrm{CD}_{3} \mathrm{OH}+h \nu \rightarrow \mathrm{CD}_{3} \mathrm{O}+\mathrm{H}, \\
& \mathrm{CD}_{3} \mathrm{OH}+h \nu \rightarrow \mathrm{CD}_{2} \mathrm{OH}+\mathrm{D} .
\end{aligned}
$$

Highly vibrationally excited $\mathrm{D}_{2}$ and $\operatorname{HD}(v=2-5)$ molecules were also produced as primary products by unimolecular elimination from methanol, i.e., reactions (10) and (11),

$$
\begin{aligned}
& \mathrm{CD}_{3} \mathrm{OH}+h \nu \rightarrow \mathrm{CDOH}+\mathrm{D}_{2}(v=2-5), \\
& \mathrm{CD}_{3} \mathrm{OH}+h \nu \rightarrow \mathrm{CD}_{2} \mathrm{O}+\mathrm{HD}(v=2-5) .
\end{aligned}
$$

Reactions (8)-(11) and the $\mathrm{C}-\mathrm{O}$ bond cleavage (7) are the primary photodissociation processes of ASM. However, the branching ratio of the primary photoprocesses could not be quantified either in our previous or the present studies.

No IR absorption signal attributable to $\mathrm{CH}_{3}$ and $\mathrm{OH}$ radicals was observed in earlier VUV photolysis studies of solid methanol at $10 \mathrm{~K} \cdot{ }^{15,16}$ These results imply that (a) the quantum yield of the $\mathrm{C}-\mathrm{O}$ bond cleavage reaction (7) on the surface under VUV irradiation is small or, (b) $\mathrm{CH}_{3}$ and $\mathrm{OH}$ photoproducts, if formed, are removed by photodesorption and reactions on/in ASM and thus remain undetected. In the following sections, possible secondary reactions of $\mathrm{CH}_{3}$ and $\mathrm{OH}$ products on/in ASM are proposed.

\section{A. $\mathrm{CH}_{3}$ radical formation in the $157 \mathrm{~nm}$ photolysis of fresh ASM}

Two MB components, characterized by $T_{\text {trans }}=3000$ and $90 \mathrm{~K}$ and with respective relative yields of $10 \%$ and $90 \%$, are required to fit the TOF spectrum of $\mathrm{CH}_{3}$ products measured at $157 \mathrm{~nm}$. The $\mathrm{CH}_{3}$ rotational temperatures for the $T_{\text {trans }}=90 \mathrm{~K}$ component are almost thermally equilibrated with the substrate temperature $(90 \mathrm{~K})$, as shown in Table I. Since $90 \%$ of the $\mathrm{CH}_{3}$ fragments are accommodated to the substrate temperature, and the translational and rotational energies are much lower than $E_{\text {avail }}(7)$, we propose that the majority of the nascent $\mathrm{CH}_{3}$ products are formed by absorption in the ASM bulk and are subsequently relaxed by collisions within the ASM en route to the vacuum. Only a small fraction (10\%) of the $\mathrm{CH}_{3}$ products are produced at the exposed ASM surface and retain a high translational temperature, i.e.,

$$
\begin{aligned}
& \mathrm{CH}_{3} \mathrm{OH}+h \nu \rightarrow \mathrm{CH}_{3}\left(T_{\text {trans }}=3000 \mathrm{~K}\right)+\mathrm{OH}, \\
& \mathrm{CH}_{3}(3000 \mathrm{~K}) \stackrel{\text { collision }}{\longrightarrow} \mathrm{CH}_{3}(90 \mathrm{~K}) .
\end{aligned}
$$

$\mathrm{CH}_{3}$ photoproducts may also be removed by reactions within the bulk and thereby remain undetected by IR absorption spectroscopy. ${ }^{15,16}$ For example, hydrogen abstraction from methanol by $\mathrm{CH}_{3}$ radicals, reactions (14) and (15), are known in the gas phase, ${ }^{41}$

$$
\begin{aligned}
& \mathrm{CH}_{3}(\mathrm{i})+\mathrm{CH}_{3} \mathrm{OH}(\text { ads }) \rightarrow \mathrm{CH}_{4}(\mathrm{i})+\mathrm{CH}_{2} \mathrm{OH}(\mathrm{i}) \text {, } \\
& \Delta H=4.2, \quad E_{\mathrm{a}}=58.6 \mathrm{~kJ} \mathrm{~mol}^{-1}, \\
& \mathrm{CH}_{3}(\mathrm{i})+\mathrm{CH}_{3} \mathrm{OH}(\text { ads }) \rightarrow \mathrm{CH}_{4}(\mathrm{i})+\mathrm{CH}_{3} \mathrm{O}(\mathrm{i}), \\
& \Delta H=33.5, \quad E_{\mathrm{a}}=56.9 \mathrm{~kJ} \mathrm{~mol}^{-1} .
\end{aligned}
$$

The quoted activation energies, $E_{\mathrm{a}}$, are ab initio estimates from MP2 and MP4 calculations reported by Jodkowski et $a l^{41}$ Some of the $\mathrm{CH}_{3}$ products formed at the ASM/vacuum interface with $\left\langle E_{\text {trans }}\right\rangle=49.8 \mathrm{~kJ} \mathrm{~mol}^{-1}$ and considerable internal energy may have sufficient energy to induce the $\mathrm{H}$ abstraction reactions (14) and (15) but, as Table I shows, most of the $\mathrm{CH}_{3}$ photoproducts relax to $T_{\text {trans }}=90 \pm 20 \mathrm{~K}$ and $T_{\text {rot }}=150 \pm 50 \mathrm{~K}$. At this stage, their average energy $\left(\sim 2.7 \mathrm{~kJ} \mathrm{~mol}^{-1}\right)$ is far too small to overcome such activation barriers. The thermally equilibrated $\mathrm{CH}_{3}$ photoproducts then diffuse through the bulk ASM until they desorb from the solid/vacuum interface. 
Other possible removal processes for $\mathrm{CH}_{3}$ include (generally barrierless) reaction with other radical photoproducts, e.g., reaction with $\mathrm{H}$-atom photoproducts to form methane,

$$
\begin{aligned}
\mathrm{CH}_{3}(\mathrm{i})+\mathrm{H}(\mathrm{i})+\mathrm{M} \rightarrow \mathrm{CH}_{4}(\mathrm{i})+\mathrm{M}, \\
\Delta H=-439.3 \mathrm{~kJ} \mathrm{~mol}^{-1} .
\end{aligned}
$$

Compared to the gas phase, we might anticipate a significant enhancement in the rate of reaction (16) in ASM since $\mathrm{H}$ atoms are very mobile, even at low temperature, and reaction (16) is a highly exothermic, three-body reaction. $\mathrm{H}$ atoms are known to be present in high density following pulsed $157 \mathrm{~nm}$ laser excitation of ASM at $90 \mathrm{~K}$, and $\mathrm{H}_{2}$ molecule formation from $\mathrm{H}$ atoms has also been reported, ${ }^{18}$ i.e.,

$$
\begin{aligned}
& \mathrm{CH}_{3} \mathrm{OH}+h \nu \rightarrow \mathrm{CH}_{2} \mathrm{OH} / \mathrm{CH}_{3} \mathrm{O}+\mathrm{H}, \\
& \mathrm{H}+\mathrm{CH}_{3} \mathrm{OH} \rightarrow \mathrm{CH}_{2} \mathrm{OH} / \mathrm{CH}_{3} \mathrm{O}+\mathrm{H}_{2}(v=0 \text { and } 1), \\
& \mathrm{H}+\mathrm{H} \rightarrow \mathrm{H}_{2}(v \geqslant 2) .
\end{aligned}
$$

Earlier VUV photolysis studies of solid methanol at $10 \mathrm{~K}$ found the yield of $\mathrm{CH}_{4}$ to depend linearly on the irradiation time, but no IR absorption signal attributable to $\mathrm{CH}_{3}$ was observed, ${ }^{15,16}$ probably because these radicals were efficiently consumed by reaction with $\mathrm{H}$ atoms, i.e., via reaction (16).

In the mixed $\mathrm{CH}_{3} \mathrm{OH} / \mathrm{H}_{2} \mathrm{O}$ ice experiment, the TOF signal intensity of the $\mathrm{CH}_{3}$ radicals was reduced. This may be due to (a) the reduction in $\mathrm{CH}_{3} \mathrm{OH}$ density on the surface, or (b) the reaction of $\mathrm{CH}_{3}$ products with $\mathrm{H}$ atoms or $\mathrm{OH}$ radicals formed from photolysis of $\mathrm{H}_{2} \mathrm{O}$. The reaction of $\mathrm{CH}_{3}$ with water molecules is unlikely: the TOF profile of $\mathrm{CH}_{3}$ radicals produced from the mixed ice showed a similar behavior to that from the fresh ASM samples, i.e., the majority of the $\mathrm{CH}_{3}$ products are accommodated to the substrate temperature $(90 \mathrm{~K})$. This implies that the $\mathrm{CH}_{3}$ products desorb without reaction with solid water, as would be expected given the large activation energy of reaction (20),

$$
\begin{aligned}
\mathrm{CH}_{3}(\mathrm{i})+\mathrm{H}_{2} \mathrm{O}(\text { ads }) & \rightarrow \mathrm{CH}_{4}(\mathrm{i})+\mathrm{OH}(\mathrm{i}), \\
\Delta H & =104.6, \quad E_{\mathrm{a}}=138.1 \mathrm{~kJ} \mathrm{~mol}^{-1} .
\end{aligned}
$$

The activation energy or reaction (20) was estimated from theoretical calculations for the reverse process, $\mathrm{CH}_{4}+\mathrm{OH}$ $\rightarrow \mathrm{CH}_{3}+\mathrm{H}_{2} \mathrm{O}$, by Bravo-Pérez et al. ${ }^{42}$

The translational temperatures of the photodesorbed $\mathrm{H}$ or $\mathrm{OH}$ products following the $157 \mathrm{~nm}$ photolysis of water ice have been previously observed with the same REMPI setup. ${ }^{38,43,44}$ The previous results showed that the majority of the photodesorbed $\mathrm{H}$ atoms were relaxed by collisions within the water ice and the translational temperature was accommodated to the substrate temperature. The photodesorbed $\mathrm{OH}$ radicals, on the other hand, were not thermally equilibrated with the substrate temperature but were likely formed near the water ice surface, whereas collisionally cooled $\mathrm{OH}$ products were either efficiently trapped in the bulk or reacted with water. ${ }^{38,43,44}$

\section{$B$. OH radical formation in the $157 \mathrm{~nm}$ photolysis of fresh ASM}

The translational energies of $\mathrm{OH}(v=0$ and 1) products from the $157 \mathrm{~nm}$ photolysis of fresh ASM are described by a single temperature $T_{\text {trans }}=3000 \pm 500 \mathrm{~K} \quad\left(\left\langle E_{\text {trans }}\right\rangle\right.$ $\left.=49.9 \pm 8.3 \mathrm{~kJ} \mathrm{~mol}^{-1}\right)$. The $\mathrm{OH}$ rotational temperatures, $T_{\text {rot }}(v=0)=300 \pm 100 \mathrm{~K}$ and $T_{\text {rot }}(v=1)=200 \pm 50 \mathrm{~K}$, are not thermally equilibrated with the substrate temperature of $90 \mathrm{~K}$, as shown in Table II. These results suggest that (a) the observed $\mathrm{OH}(v=0$ and 1) fragments originate from the ASM surface, not the bulk, and (b) $\mathrm{OH}(v=0$ and 1) radicals formed in the ASM bulk are either efficiently trapped or react in the bulk as described before in the $157 \mathrm{~nm}$ photolysis of $\mathrm{H}_{2} \mathrm{O},{ }^{37,38}$ i.e.,

$$
\begin{aligned}
& \mathrm{CH}_{3} \mathrm{OH}+h \nu \rightarrow \mathrm{CH}_{3}+\mathrm{OH}\left(T_{\text {trans }}=3000 \mathrm{~K}\right), \\
& \mathrm{OH}(3000 \mathrm{~K}) \stackrel{\text { collision }}{\longrightarrow} \text { trapped or react with ASM. }
\end{aligned}
$$

Possible $\mathrm{H}$ abstraction reactions from methanol by $\mathrm{OH}$ radicals are

$$
\begin{array}{r}
\mathrm{OH}(\mathrm{i})+\mathrm{CH}_{3} \mathrm{OH}(\text { ads }) \rightarrow \mathrm{H}_{2} \mathrm{O}(\mathrm{i})+\mathrm{CH}_{2} \mathrm{OH}(\mathrm{i}), \\
\Delta H=-50.2, \quad E_{\mathrm{a}}=3.8 \mathrm{~kJ} \mathrm{~mol}^{-1}, \\
\mathrm{OH}(\mathrm{i})+\mathrm{CH}_{3} \mathrm{OH}(\text { ads }) \rightarrow \mathrm{H}_{2} \mathrm{O}(\mathrm{i})+\mathrm{CH}_{3} \mathrm{O}(\mathrm{i}), \\
\Delta H=-25.1, \quad E_{\mathrm{a}}=14.6 \mathrm{~kJ} \mathrm{~mol}^{-1} .
\end{array}
$$

The activation energies quoted are for the corresponding gas phase reactions, estimated by Jodkowski et al. ${ }^{41}$ Reaction (23) has been proposed previously in methanol-water condensed phase systems. ${ }^{45}$ Recalling Table II, the $\mathrm{OH}$ products from the $157 \mathrm{~nm}$ photolysis of ASM have ample energy to overcome the barriers for reactions (23) and (24), and thus $\mathrm{OH}$ radical initiated hydrogen abstraction is likely to occur on/in ASM.

However, neither photodesorption nor production of $\mathrm{H}_{2} \mathrm{O}$ was observed in either the present or earlier VUV photolysis studies on ASM. ${ }^{15,16}$ These results imply that the yield of $\mathrm{OH}$ production via the $\mathrm{C}-\mathrm{O}$ bond cleavage reaction (7) on the surface is small and that the secondary $\mathrm{H}_{2} \mathrm{O}$ formation via reactions (23) and (24) does not proceed efficiently.

\section{Other possible secondary reactions}

After photolysis of a $\mathrm{CH}_{3} \mathrm{OH}$ molecule in bulk ASM, the probability of reaction (25) is expected to be high since the photogenerated $\mathrm{CH}_{3}$ and $\mathrm{OH}$ radicals are effectively caged by the ASM matrix, ${ }^{17,46,47}$ i.e.,

$$
\begin{array}{r}
\mathrm{CH}_{3}(\mathrm{i})+\mathrm{OH}(\mathrm{i})+\mathrm{M} \rightarrow \mathrm{CH}_{3} \mathrm{OH}(\text { ads })+\mathrm{M}, \\
\Delta H=-422.6 \mathrm{~kJ} \mathrm{~mol}^{-1},
\end{array}
$$

the bimolecular reaction between gas phase $\mathrm{CH}_{3}$ and $\mathrm{OH}$ radicals has been studied extensively, both theoretically and experimentally. ${ }^{48}$ The calculations of Jasper et al. show a number of reactive radicals and molecular products from this 
reaction, e.g., $\mathrm{CH}_{3} \mathrm{OH}, \mathrm{HCOH}+\mathrm{H}_{2}$, and $\mathrm{CH}_{2}+\mathrm{H}_{2} \mathrm{O}{ }^{48}$ In the condensed phase, Hodyss et al. reported a UV $(130-335 \mathrm{~nm})$ photolysis study of $\mathrm{CH}_{4}-\mathrm{H}_{2} \mathrm{O}$ ice mixtures at $20 \mathrm{~K}^{49}$ Their analysis assumes that $\mathrm{OH}$ radicals formed by the photodissociation of water react with methane to form $\mathrm{CH}_{3}$ radicals, which then recombine with $\mathrm{OH}$ radicals to form methanol.

Ethane formation, from the recombination reaction of two $\mathrm{CH}_{3}$ radicals [reaction (26)], was also reported in the photolysis of $\mathrm{CH}_{4}-\mathrm{H}_{2} \mathrm{O}$ ice mixtures, ${ }^{49}$

$$
\begin{aligned}
\mathrm{CH}_{3}(\mathrm{i})+\mathrm{CH}_{3}(\mathrm{i})+\mathrm{M} & \rightarrow \mathrm{C}_{2} \mathrm{H}_{6}(\mathrm{i})+\mathrm{M}, \\
\Delta H & =-376.6 \mathrm{~kJ} \mathrm{~mol}^{-1} .
\end{aligned}
$$

No IR absorption attributable to $\mathrm{C}_{2} \mathrm{H}_{6}$ was observed in the earlier VUV photolysis studies of solid $\mathrm{CH}_{3} \mathrm{OH}$ at $10 \mathrm{~K}$, however. ${ }^{15,16}$ This finding is understandable if $\mathrm{CH}_{3}$ photoproducts react with other species (e.g., $\mathrm{H}, \mathrm{OH}$, or $\mathrm{CH}_{3} \mathrm{OH}$ ) much more frequently than they encounter another $\mathrm{CH}_{3}$ radical.

Hodyss et al. ${ }^{49}$ proposed that the presence of $\mathrm{CH}_{4}$ in $\mathrm{CH}_{4}-\mathrm{H}_{2} \mathrm{O}$ ice mixtures inhibited the formation of $\mathrm{H}_{2} \mathrm{O}_{2}$ (from the combination of two $\mathrm{OH}$ radicals) by serving as a trap for $\mathrm{OH}$ radicals, since the $\mathrm{C}-\mathrm{H}$ bonds are also attacked by $\mathrm{OH}$ radicals. In fact, no IR absorption features attributable to $\mathrm{H}_{2} \mathrm{O}_{2}$ or $\mathrm{OH}$ were observed in the VUV photolysis of solid $\mathrm{CH}_{3} \mathrm{OH}$ at $10 \mathrm{~K} \cdot{ }^{15,16}$ Our previous experimental work has confirmed that $\mathrm{OH}$ radicals are formed following the $157 \mathrm{~nm}$ photolysis of $\mathrm{H}_{2} \mathrm{O}_{2}$ photoproducts on the ASW surface as well as by primary photolysis of surface $\mathrm{H}_{2} \mathrm{O}$, and that the translational energy of $\mathrm{OH}$ radicals from $\mathrm{H}_{2} \mathrm{O}_{2}$ was much larger than that from $\mathrm{H}_{2} \mathrm{O}{ }^{38}$ There are no discernible differences in the TOF spectra, or the rotational resolved REMPI spectra, of the $\mathrm{OH}$ radicals from the $157 \mathrm{~nm}$ photolysis of fresh or photoirradiated ASM samples, i.e., the $\mathrm{OH}$ radicals detected in the present study are produced directly, via reaction (7), and not from secondary photolysis of photogenerated $\mathrm{H}_{2} \mathrm{O}_{2}$.

\section{CONCLUSION}

The translational and rotational temperatures of $\mathrm{CH}_{3}(v$ $=0)$ and $\mathrm{OH}(v=0$ and 1$)$ radicals (i.e., the products from the primary $\mathrm{C}-\mathrm{O}$ bond cleavage) have been measured following pulsed $157 \mathrm{~nm}$ irradiation of ASM at $90 \mathrm{~K}$. Most of the detected $\mathrm{CH}_{3}$ species have low translational and internal energies, implying that these photoproducts accommodate to the ASM bulk temperature and desorb from the ASM surface without reaction in the bulk near the solid/vacuum interface. The detected $\mathrm{OH}$ fragments, in contrast, are deduced to originate exclusively from the ASM surface; any $\mathrm{OH}$ radicals formed in the ASM bulk phase are readily trapped or react in the bulk phase. The equivalence of the TOF spectra of $\mathrm{CH}_{3}$ fragments from ASM and from a mixed $\mathrm{CH}_{3} \mathrm{OH}-\mathrm{H}_{2} \mathrm{O}$ ice sample indicates that the reactivity of solid water with $\mathrm{CH}_{3}$ products is small.

\section{ACKNOWLEDGMENTS}

This work was supported by a Grant-in-Aid from JSPS (Grant No. 20245005). M.K. and M.N.R.A. remain very grateful for the award of a Daiwa-Adrian prize that facilitated earlier phases of this collaboration. P.W., W.G., and H.P.L. acknowledge financial support from the Natural Sciences and Engineering Research Council of Canada.

${ }^{1}$ S. Harich, J. J. Lin, Y. T. Lee, and X. Yang, J. Chem. Phys. 111, 5 (1999).

${ }^{2}$ S. Harich, J. J. Lin, Y. T. Lee, and X. Yang, J. Phys. Chem. A 103, 10324 (1999).

${ }^{3}$ S. H. Lee, H. I. Lee, and Y. T. Lee, J. Chem. Phys. 121, 11053 (2004).

${ }^{4}$ Y. Wen, J. Segall, M. Dulligan, and C. Wittig, J. Chem. Phys. 101, 5665 (1994).

${ }^{5}$ S. Pilling, R. Neves, A. C. F. Santos, and H. M. Boechat-Roberty, Astron. Astrophys. 464, 393 (2007).

${ }^{6}$ S. Satyapal, J. Park, R. Bersohn, and B. J. Katz, J. Chem. Phys. 91, 6873 (1989).

${ }^{7}$ B.-M. Cheng, C.-P. Liu, W.-J. Lo, and Y.-P. Lee, Nucl. Instrum. Methods Phys. Res. A 467, 1461 (2001).

${ }^{8}$ K. M. Pontoppidan, E. Dartois, E. F. van Dishoeck, W. F. Thi, and L. d'Hendecourt, Astron. Astrophys. 404, L17 (2003).

${ }^{9}$ M. J. Mumma, M. A. DiSanti, K. Magee-Sauer, B. P. Bonev, G. L. Villanueva, H. Kawakita, N. D. Russo, E. L. Gibb, G. A. Blake, J. E. Lyke, R. D. Campbell, J. Aycock, A. Conrad, and G. M. Hill, Science 310, 270 (2005).

${ }^{10}$ D. P. Cruikshank, T. L. Roush, M. J. Bartholomew, T. R. Geballe, Y. J. Pendleton, S. M. White, J. F. Bell III, J. K. Davies, T. C. Owen, C. de Bergh, D. J. Tholen, M. P. Bernstein, R. H. Brown, K. A. Tryka, and C. M. Dalle Ore, Icarus 135, 389 (1998).

${ }^{11}$ D. P. Cruikshank, T. L. Roush, and F. Poulet, C. R. Phys. 4, 783 (2003).

${ }^{12}$ C. J. Bennett, S.-H. Chen, B.-J. Sun, A. H. H. Chang, and R. I. Kaiser, Astrophys. J. 660, 1588 (2007).

${ }^{13}$ G. A. Baratta, G. Leto, and M. E. Palumbo, Astron. Astrophys. 384, 343 (2002).

${ }^{14}$ G. A. Baratta, A. C. Castorina, G. Leto, M. E. Palumbo, F. Spinella, and G. Strazzulla, Planet. Space Sci. 42, 759 (1994).

${ }^{15}$ W. A. Schutte and P. A. Gerakines, Planet. Space Sci. 43, 1253 (1995).

${ }^{16}$ P. A. Gerakines, W. A. Schutte, and P. Ehrenfreund, Astron. Astrophys. 312, 289 (1996).

${ }^{17}$ Y.-P. Kuo, H.-C. Lu, Y.-J. Wu, B.-M. Cheng, and J. F. Ogilvie, Chem. Phys. Lett. 447, 168 (2007).

${ }^{18}$ T. Hama, M. Yokoyama, A. Yabushita, and M. Kawasaki, J. Chem. Phys. 130, 164505 (2009).

${ }^{19}$ A. Yabushita, Y. Inoue, T. Senga, M. Kawasaki, and S. Sato, J. Phys. Chem. B 106, 3151 (2002).

${ }^{20}$ N. G. Petrik and G. A. Kimmel, J. Phys. Chem. C 113, 4451 (2009).

${ }^{21}$ N. G. Petrik, A. G. Kavetsky, and G. A. Kimmel, J. Chem. Phys. 125, 124702 (2006).

${ }^{22}$ S. M. Dounce, J. Mundy, and H. L. Dai, J. Chem. Phys. 126, 191111 (2007).

${ }^{23}$ A. Yabushita, T. Hama, D. Iida, N. Kawanaka, M. Kawasaki, N. Watanabe, M. N. R. Ashfold, and H.-P. Loock, Astrophys. J. 682, L69 (2008).

${ }^{24}$ J. F. Black and I. Powis, J. Chem. Phys. 89, 3986 (1988).

${ }^{25}$ M. E. Greenslade, M. I. Lester, D. C. Radenovic, A. J. A. van Roij, and D. H. Parker, J. Chem. Phys. 123, 074309 (2005).

${ }^{26} \mathrm{C}$. M. Western, PGOPHER, a program for simulating rotational structure, University of Bristol, available at http://pgopher.chm.bris.ac.uk.

${ }^{27}$ S. T. Pratt, P. M. Dehmer, and J. L. Dehmer, Phys. Rev. A 43, 4702 (1991).

${ }^{28}$ Y. Matsumi, N. Shafer, K. Tonokura, M. Kawasaki, Y.-L. Huang, and R. J. Gordon, J. Chem. Phys. 95, 7311 (1991).

${ }^{29}$ A. Yabushita, T. Hama, M. Yokoyama, M. Kawasaki, S. Andersson, R. N. Dixon, M. N. R. Ashfold, and N. Watanabe, Astrophys. J. 699, L80 (2009).

${ }^{30}$ T. Hama, A. Yabushita, M. Yokoyama, M. Kawasaki, and N. Watanabe, J. Chem. Phys. 131, 114510 (2009).

${ }^{31}$ T. Hama, A. Yabushita, M. Yokoyama, M. Kawasaki, and N. Watanabe, J. Chem. Phys. 131, 114511 (2009).

${ }^{32}$ K. P. Huber and G. Herzberg (data prepared by J. W. Gallagher and R. D. Johnson, III), "Constants of Diatomic Molecules," in NIST Chemistry 
WebBook, NIST Standard Reference Database Number 69, P. J. Linstrom and W. G. Mallard, National Institute of Standards and Technology, Gaithersburg, MD, 20899, see http://webbook.nist.gov/ (retrieved 2009).

${ }^{33}$ F. M. Zimmermann and W. Ho, J. Chem. Phys. 100, 7700 (1994).

${ }^{34}$ F. M. Zimmermann and W. Ho, Surf. Sci. Rep. 22, 127 (1995).

${ }^{35}$ A. Yabushita, Y. Inoue, T. Senga, M. Kawasaki, and S. Sato, J. Phys. Chem. A 108, 438 (2004).

${ }^{36}$ P. Quintana, R. F. Delmdahl, D. H. Parker, B. Martinez-Haya, F. J. Aoiz, L. Banares, and E. Verdasco, Chem. Phys. Lett. 325, 146 (2000).

${ }^{37}$ A. Yabushita, T. Hama, D. Iida, and M. Kawasaki, J. Chem. Phys. 129, 014709 (2008).

${ }^{38}$ T. Hama, A. Yabushita, M. Yokoyama, M. Kawasaki, and S. Andersson, J. Chem. Phys. 131, 054508 (2009).

${ }^{39}$ M. Kh. Karapet'yants and M. K. Karapet'yants, Handbook of Thermodynamic Constants of Inorganic and Organic Compounds (Ann ArborHumphrey Science, London, 1970).

${ }^{40}$ S. P. Sander, R. R. Friedl, A. R. Ravishankara, D. M. Golden, C. E. Kolb, M. J. Kurylo, M. J. Molina, G. K. Moortgat, H. Keller-Rudek, B. J. Finlayson-Pitts, P. H. Wine, R. E. Huie, and V. L. Orkin, Chemical Kinetics and Photochemical Data for Use in Atmospheric Studies Evalua- tion No. 15 (2006)

${ }^{41}$ J. T. Jodkowski, M.-T. Rayez, J.-C. Rayez, T. Bérces, and S. Dóbé, J. Phys. Chem. A 103, 3750 (1999).

${ }^{42}$ G. Bravo-Pérez, J. R. Alvarez-Idaboy, A. G. Jiménez, and A. CruzTorres, J. Chem. Phys. 310, 213 (2005).

${ }^{43}$ A. Yabushita, Y. Hashikawa, A. Ikeda, M. Kawasaki, and H. Tachikawa, J. Chem. Phys. 120, 5463 (2004).

${ }^{44}$ A. Yabushita, D. Kanda, N. Kawanaka, M. Kawasaki, and M. N. R. Ashfold, J. Chem. Phys. 125, 133406 (2006).

${ }^{45}$ M. C. Akin, N. G. Petrik, and G. A. Kimmel, J. Chem. Phys. 130, 104710 (2009).

${ }^{46}$ S. Andersson, A. Al-Halabi, G.-J. Kroes, and E. F. van Dishoeck, J. Chem. Phys. 124, 064715 (2006).

${ }^{47}$ S. Andersson and E. F. van Dishoeck, Astron. Astrophys. 491, 907 (2008)

${ }^{48}$ A. W. Jasper, S. J. Klippenstein, L. B. Harding, and B. Ruscic, J. Phys. Chem. A 111, 3932 (2007).

${ }^{49}$ R. Hodyss, P. V. Johnson, J. V. Stern, J. D. Goguen, and I. Kanik, Icarus 200, 338 (2009). 